\title{
Associations of foot ulceration with quality of life and psychosocial determinants among patients with diabetes; a case- control study
}

Fahad D. Alosaimi ${ }^{1,2^{*}}$ (D) Reem Labani ${ }^{3}$, Nouf Almasoud ${ }^{3}$, Nora Alhelali ${ }^{3}$, Lamya Althawadi ${ }^{3}$ and Dhaherah Mani AlJahani ${ }^{3}$

\begin{abstract}
Background: Patients with diabetic foot ulcers may have a lower quality of life. The objective was to compare the quality of life and its psychosocial determinants among patients with and without diabetic foot ulcers.

Methods: A case-control study was conducted in 2017 among patients with (cases) and without (controls) diabetic foot ulcers. The study tools included the World Health Organization's Quality of Life scale (WHOQOL-BREF), the Hospital Anxiety and Depression (HAD) scale for anxiety and depression, the Patient Health Questionnaire Physical Symptoms (PHQ-15) for the severity of somatic symptoms, and the Summary of Diabetes Self-Care Activities (SDSCA) measure for self-management.

Results: A total of 209 patients (45 cases and 164 controls) were included. The average age was $56.2 \pm 11.7$ years, and $55.5 \%$ were female. The average scores of WHOQOL-BREF, PHQ-15, and SDSCA were $74.4 \% \pm 12.1 \%$ and $8.1 \pm 6.1$, and $30.4 \pm 21.8$, respectively. The prevalence of anxiety and depression were 19.6 and 24.9\%, respectively. SDSCA was the only psychosocial determinants higher in cases than controls (mean difference $=$ 15.0, 95\% Cl=-8.0-22.0). The correlation coefficients of WHOQOL-BREF scores with anxiety, depression, and PHQ-15 scores in all patients were $-0.559(p<0.001),-0.582(p<0.001)$, and $-0.532(p<0.001)$, respectively, with similar numbers in both groups. In multivariate analysis, only the association between quality of life and depression was maintained.
\end{abstract}

Conclusion: Quality of life and psychosocial determinants with the exception of self-management were not associated with diabetic foot ulcers. Depressive symptoms were independent determinant of poor quality of life, irrespective of the status of diabetic foot ulcers.

Keywords: Diabetic foot, Quality of life, Anxiety, Depression, Saudi Arabia

\footnotetext{
* Correspondence: dr.fahad.alosaimi@gmail.com

'Department of Psychiatry, King Saud University, Riyadh, Saudi Arabia

2Department of Psychiatry, College of medicine, King Saud University, P.O.

Box: 7805, Riyadh Postcode:11472, Saudi Arabia

Full list of author information is available at the end of the article
}

(c) The Author(s). 2019 Open Access This article is distributed under the terms of the Creative Commons Attribution 4.0 International License (http://creativecommons.org/licenses/by/4.0/), which permits unrestricted use, distribution, and reproduction in any medium, provided you give appropriate credit to the original author(s) and the source, provide a link to the Creative Commons license, and indicate if changes were made. The Creative Commons Public Domain Dedication waiver (http://creativecommons.org/publicdomain/zero/1.0/) applies to the data made available in this article, unless otherwise stated. 


\section{Background}

According to recent reports of the International Diabetes Federation, the prevalence of diabetes in Saudi Arabia was estimated at $18.5 \%$, which is considered one of the highest in the world [1]. In 2017, it was estimated that approximately 3.8 million patients had diabetes in Saudi Arabia, with 15,000 diabetes-related deaths annually [1]. Diabetic foot disease is a common chronic diabetic complication and typically presents as ulcers with or without infection, in the presence of peripheral neuropathy or peripheral vascular disease [2]. Diabetic foot ulcers affect approximately $8.5 \%$ (range $1.8-19 \%$ ) of the patients with diabetes in Saudi Arabia [3]. This is higher than global prevalence that has been estimated at $6.3 \%$ (95\% confidence interval, 5.4-7.3\%) [4]. Self-management including specific footcare practices has been recognized as an important preventive measure for diabetic foot ulcers $[5,6]$.

Diabetic foot ulcers can lead to a significant increase in mortality and lower limb amputations [7, 8]. According to the Saudi National Diabetes Registry, diabetic foot ulcers increase the mortality of diabetic patients by almost two-fold [9]. Additionally, diabetic foot ulcers increase hospital admissions and emergency visits, representing a significant financial burden for patients and healthcare system $[10,11]$. Furthermore, diabetic foot ulcers, which are frequently associated with pain and discomfort, have been shown to negatively impact various domains of quality of life in both international $[12,13]$ and local studies $[14,15]$. This association was observed especially in patients who underwent amputations [11] and may be related to the impacts of limited physical functioning, psychological problems, financial burden, and poor social situations $[13,16]$. Previous studies showed a link between anxiety/depression and poor quality of life among patients with diabetic foot ulcers $[17,18]$.

Unlike the traditional risk factors of diabetic foot ulcers in Saudi Arabia [19, 20], psychosocial determinants [21] and quality of life $[14,15]$ in these patients have received little attention. Additionally, there is a lack of studies examining psychosocial and other related determinants of quality of life. The objective of the current study was to compare the quality of life and its psychosocial determinants (anxiety, depression, severity of somatic symptoms, and self-management) among patients with and without diabetic foot ulcers. A secondary objective was to assess the associations of these psychosocial determinants with the quality of life.

\section{Methods}

\section{Setting}

The current study was conducted at the diabetic center and the primary care clinic of King Saud University Medical City in Riyadh (KSUMC), Saudi Arabia.
KSUMC is a 1000-bed tertiary care medical teaching facility affiliated with King Saud University. KSUMC is governmentally funded and provides free primary to tertiary healthcare services for primarily patients living in the Riyadh region.

\section{Study design}

A case-control study was conducted between March and August 2017. Patients who were diagnosed with diabetic foot ulcers at the time of study were considered cases. Patients who were not diagnosed with diabetic foot ulcers at the time of study (other than painful peripheral neuropathy) were considered controls. Diabetic foot ulcers were defined as per the International Working Group on the Diabetic Foot; breaks in the skin of the foot in a patient with diabetes, commonly associated with infection, neuropathy and/or peripheral arterial disease [2]. Cases and controls were group-matched by age and sex. Ethical approval was acquired from the institutional review board at the Faculty of Medicine at King Saud University in Riyadh, Saudi Arabia.

\section{Population}

The target population was conveniently recruited from adult patients with diabetes receiving diabetic care at the diabetic center or the primary care clinic of KSUMC. Patients with serious late complications of diabetes, such as dialysis and blindness, were excluded. Patients with difficulty communicating, such as those with a language barrier or severe cognitive impairment, were excluded. There were no exclusions based on the type of diabetes, comorbidities, or glycemic control.

\section{Sample size}

The quality of life score was assumed to be lower in patients with diabetic foot ulcers than in those without diabetic foot ulcers. As the prevalence of diabetic foot ulcers was small, 4 controls were chosen for each case. It was estimated that 40 cases and 160 controls would be required to detect a $10 \%$ difference between the two groups $(50 \% \pm 20 \%$ versus $60 \% \pm 20 \%)$, based on $80 \%$ power and 95\% significance levels. OpenEpi Version 2.2 (http://www.openepi.com) was used for sample size calculation.

\section{Instruments}

A structured study questionnaire that was developed by the study investigators was used to collect the patient information. The information collected included sociodemographic characteristics (Table 1), clinical history (Table 2), and psychological history (top part of Table 3). Additionally, patients' records were reviewed to detect comorbidities. Standardized tools were used to collect data on the study outcomes. 
Table 1 Demographic characteristics of 209 Saudi diabetic patients by diabetic foot ulcer status ${ }^{a}$

\begin{tabular}{|c|c|c|c|c|c|}
\hline & \multicolumn{2}{|c|}{ Diabetic foot ulcers } & \multirow{2}{*}{$\begin{array}{l}\text { Total } \\
(N=209)\end{array}$} & \multirow{2}{*}{$\begin{array}{l}\text { Magnitude of } \\
\text { difference }\end{array}$} & \multirow[t]{2}{*}{$p$-value } \\
\hline & Yes $(n=45)$ & No $(n=164)$ & & & \\
\hline \multicolumn{6}{|l|}{ Age (years) } \\
\hline Mean \pm SD & $56.7 \pm 12.3$ & $56.1 \pm 11.6$ & $56.2 \pm 11.7$ & $0.7(-3.3-4.6)$ & 0.740 \\
\hline$<60$ & $24(54.5 \%)$ & 99 (61.5\%) & $123(60.0 \%)$ & - & 0.405 \\
\hline$\geq 60$ & $20(45.5 \%)$ & $62(38.5 \%)$ & $82(40.0 \%)$ & $1.36(0.69-2.66)$ & \\
\hline Weight (kg) & $88.8 \pm 20.4$ & $82.2 \pm 20.2$ & $83.6 \pm 20.4$ & $6.6(-1.1-14.3)$ & 0.091 \\
\hline Height (cm) & $165.4 \pm 8.7$ & $161.8 \pm 8.8$ & $162.6 \pm 8.9$ & $3.6(0.2-7.0)$ & 0.037 \\
\hline \multicolumn{6}{|l|}{ Body mass index } \\
\hline Mean \pm SD & $32.7 \pm 7.8$ & $31.7 \pm 7.6$ & $31.9 \pm 7.6$ & $1.0(-2.0-4.0)$ & 0.509 \\
\hline Normal & $4(12.1 \%)$ & $19(16.5 \%)$ & $23(15.5 \%)$ & - & 0.743 \\
\hline Overweight & $11(33.3 \%)$ & $32(27.8 \%)$ & $43(29.1 \%)$ & $1.72(0.48-6.14)$ & \\
\hline Obese & $18(54.5 \%)$ & $64(55.7 \%)$ & $82(55.4 \%)$ & $1.41(0.43-4.64)$ & \\
\hline \multicolumn{6}{|l|}{ Gender } \\
\hline Male & $23(51.1 \%)$ & $70(42.7 \%)$ & $93(44.5 \%)$ & $1.43(0.74-2.78)$ & 0.314 \\
\hline Female & $22(48.9 \%)$ & $94(57.3 \%)$ & 116 (55.5\%) & - & \\
\hline \multicolumn{6}{|l|}{ Marital status } \\
\hline Single & $3(6.7 \%)$ & $7(4.3 \%)$ & $10(4.8 \%)$ & - & 0.197 \\
\hline Married & $33(73.3 \%)$ & $132(80.5 \%)$ & 165 (78.9\%) & $0.75(0.19-2.93)$ & \\
\hline Widow & $5(11.1 \%)$ & $21(12.8 \%)$ & $26(12.4 \%)$ & $0.71(0.14-3.65)$ & \\
\hline Divorced & $4(8.9 \%)$ & $4(2.4 \%)$ & $8(3.8 \%)$ & $3.0(0.45-20.15)$ & \\
\hline \multicolumn{6}{|l|}{ Educational level } \\
\hline Illiterate & 7 (16.3\%) & $34(21.4 \%)$ & $41(20.3 \%)$ & - & 0.407 \\
\hline Less than high school & 17 (39.5\%) & $43(27.0 \%)$ & $60(29.7 \%)$ & $1.92(0.72-5.16)$ & \\
\hline High school & $10(23.3 \%)$ & $37(23.3 \%)$ & $47(23.3 \%)$ & $1.31(0.45-3.84)$ & \\
\hline University or above & 9 (20.9\%) & $45(28.3 \%)$ & $54(26.7 \%)$ & $0.97(0.33-2.87)$ & \\
\hline \multicolumn{6}{|l|}{ Occupation } \\
\hline Field job & $3(6.7 \%)$ & 15 (9.1\%) & $18(8.6 \%)$ & $0.79(0.21-3.02)$ & 0.651 \\
\hline Office job & $9(20.0 \%)$ & $21(12.8 \%)$ & $30(14.4 \%)$ & $1.69(0.66-4.31)$ & \\
\hline Housewife & $15(33.3 \%)$ & $57(34.8 \%)$ & $72(34.4 \%)$ & $1.04(0.48-2.24)$ & \\
\hline Not working & $18(40.0 \%)$ & $71(43.3 \%)$ & $89(42.6 \%)$ & - & \\
\hline \multicolumn{6}{|l|}{ Monthly family income (SR) } \\
\hline$<5000$ & $20(47.6 \%)$ & $55(36.2 \%)$ & 75 (38.7\%) & - & 0.172 \\
\hline 5000-9999 & $12(28.6 \%)$ & $48(31.6 \%)$ & $60(30.9 \%)$ & $0.69(0.31-1.55)$ & \\
\hline $10,000-14,999$ & $8(19.0 \%)$ & $23(15.1 \%)$ & $31(16.0 \%)$ & $0.96(0.37-2.48)$ & \\
\hline$\geq 15,000$ & $2(4.8 \%)$ & $26(17.1 \%)$ & $28(14.4 \%)$ & $0.21(0.05-0.97)$ & \\
\hline \multicolumn{6}{|c|}{ Number of family members } \\
\hline Mean \pm SD & $6.8 \pm 3.1$ & $7.0 \pm 3.4$ & $7.0 \pm 3.3$ & $-0.2(-1.4-0.9)$ & 0.718 \\
\hline \multicolumn{6}{|l|}{ Living alone } \\
\hline No & $39(86.7 \%)$ & $143(88.3 \%)$ & $182(87.9 \%)$ & - & 0.770 \\
\hline Yes & $6(13.3 \%)$ & 19 (11.7\%) & $25(12.1 \%)$ & $1.16(0.43-3.10)$ & \\
\hline
\end{tabular}

${ }^{a}$ Number (frequency) unless noted otherwise; SD standard deviation. ${ }^{\mathrm{b}}$ Magnitude of difference between cases and control; odds ratio (for categorical data) or mean difference (for continuous data) plus $95 \%$ confidence interval. Empty cells means reference group 
Table 2 Clinical characteristics of 209 Saudi diabetic patients by diabetic foot ulcer status $^{\mathrm{a}}$

\begin{tabular}{|c|c|c|c|c|c|}
\hline & \multicolumn{2}{|c|}{ Diabetic foot ulcers } & \multirow{2}{*}{$\begin{array}{l}\text { Total } \\
(N=209)\end{array}$} & \multirow{2}{*}{$\begin{array}{l}\text { Magnitude of } \\
\text { difference }\end{array}$} & \multirow[t]{2}{*}{$p$-value } \\
\hline & Yes $(n=45)$ & No $(n=164)$ & & & \\
\hline \multicolumn{6}{|l|}{ Type of diabetes } \\
\hline Type 1 & $4(8.9 \%)$ & $33(20.1 \%)$ & $37(17.7 \%)$ & $0.21(0.06-0.75)$ & \multirow[t]{3}{*}{0.033} \\
\hline Type 2 & $29(64.4 \%)$ & $110(67.1 \%)$ & $139(66.5 \%)$ & $0.46(0.20-1.05)$ & \\
\hline Unknown & $12(26.7 \%)$ & $21(12.8 \%)$ & $33(15.8 \%)$ & - & \\
\hline \multicolumn{6}{|l|}{$\mathrm{HbA1c}$} \\
\hline Mean \pm SD & $9.9 \pm 2.7$ & $8.4 \pm 2.0$ & $8.6 \pm 2.2$ & $1.5(0.3-2.7)$ & 0.016 \\
\hline$\geq 8$ & $18(78.3 \%)$ & $53(54.1 \%)$ & $71(58.7 \%)$ & $3.06(1.05-8.89)$ & \multirow[t]{2}{*}{0.034} \\
\hline$<8$ & $5(21.7 \%)$ & $45(45.9 \%)$ & $50(41.3 \%)$ & - & \\
\hline Age at diagnosis of diabetes & $37.6 \pm 12.0$ & $42.7 \pm 12.0$ & $41.6 \pm 12.1$ & $-5.1(-9.1--1.1)$ & 0.014 \\
\hline \multicolumn{6}{|l|}{ Family history of diabetes } \\
\hline No & $14(31.1 \%)$ & $46(28.0 \%)$ & $60(28.7 \%)$ & - & \multirow[t]{2}{*}{0.688} \\
\hline Yes & $31(68.9 \%)$ & $118(72.0 \%)$ & $149(71.3 \%)$ & $0.86(0.42-1.77)$ & \\
\hline \multicolumn{6}{|l|}{ Symptoms } \\
\hline Peripheral tingling & $23(52.3 \%)$ & $68(42.5 \%)$ & $91(44.6 \%)$ & $1.48(0.76-2.89)$ & 0.248 \\
\hline Peripheral numbness & $35(79.5 \%)$ & $78(48.8 \%)$ & $113(55.4 \%)$ & $4.09(1.85-9.06)$ & $<0.001$ \\
\hline Peripheral hypo- or hyperthermia & $20(45.5 \%)$ & $70(43.8 \%)$ & $90(44.1 \%)$ & $1.07(0.55-2.10)$ & 0.840 \\
\hline Peripheral painlessness & $17(38.6 \%)$ & $16(10.0 \%)$ & $33(16.2 \%)$ & $5.67(2.55-12.57)$ & $<0.001$ \\
\hline Peripheral edema & $10(22.7 \%)$ & $39(24.4 \%)$ & 49 (24.0\%) & $0.91(0.41-2.02)$ & 0.821 \\
\hline Tiredness without working & $15(34.1 \%)$ & $80(50.0 \%)$ & $95(46.6 \%)$ & $0.52(0.26-1.04)$ & 0.061 \\
\hline Blurred vision & $20(45.5 \%)$ & $54(33.8 \%)$ & $74(36.3 \%)$ & $1.64(0.83-3.22)$ & 0.153 \\
\hline Nocturnal dyspnea & $4(9.1 \%)$ & $27(16.9 \%)$ & $31(15.2 \%)$ & $0.49(0.16-1.49)$ & 0.203 \\
\hline Loss of concentration & $13(29.5 \%)$ & $35(21.9 \%)$ & $48(23.5 \%)$ & $1.50(0.71-3.17)$ & 0.288 \\
\hline Amputation & $10(22.7 \%)$ & $0(0.0 \%)$ & $10(4.9 \%)$ & NA & $<0.001$ \\
\hline \multicolumn{6}{|l|}{ Number of comorbid diseases } \\
\hline Mean \pm SD & $2.9 \pm 1.9$ & $2.8 \pm 2.0$ & $2.8 \pm 2.0$ & $0.1(-0.5-0.8)$ & 0.702 \\
\hline None & $5(11.1 \%)$ & $19(11.7 \%)$ & $24(11.5 \%)$ & - & \multirow[t]{3}{*}{0.715} \\
\hline One or two & $16(35.6 \%)$ & $68(41.7 \%)$ & $84(40.4 \%)$ & $0.89(0.29-2.76)$ & \\
\hline Three or more & $24(53.3 \%)$ & $76(46.6 \%)$ & $100(48.1 \%)$ & $1.20(0.41-3.56)$ & \\
\hline \multicolumn{6}{|l|}{ Comorbidity } \\
\hline Hypercholesterolemia & $20(44.4 \%)$ & $97(59.5 \%)$ & $117(56.3 \%)$ & $0.54(0.28-1.06)$ & 0.071 \\
\hline Hypertension & $28(62.2 \%)$ & $76(46.6 \%)$ & $104(50.0 \%)$ & $1.89(0.96-3.71)$ & 0.064 \\
\hline Joint diseases & $10(22.2 \%)$ & $61(37.4 \%)$ & $71(34.1 \%)$ & $0.48(0.22-1.03)$ & 0.057 \\
\hline Cataracts & $11(24.4 \%)$ & $32(19.6 \%)$ & $43(20.7 \%)$ & $1.32(0.61-2.90)$ & 0.480 \\
\hline Cardiovascular diseases & $12(26.7 \%)$ & $29(17.8 \%)$ & $41(19.7 \%)$ & $1.68(0.78-3.64)$ & 0.185 \\
\hline Retinal disease & $14(31.1 \%)$ & $20(12.3 \%)$ & $34(16.3 \%)$ & $3.23(1.47-7.08)$ & 0.002 \\
\hline Gastrointestinal disease & $5(11.1 \%)$ & $26(16.0 \%)$ & 31 (14.9\%) & $0.66(0.24-1.83)$ & 0.420 \\
\hline Lung disease & $5(11.1 \%)$ & $24(14.7 \%)$ & 29 (13.9\%) & $0.72(0.26-2.02)$ & 0.536 \\
\hline Anemia & $4(8.9 \%)$ & $25(15.3 \%)$ & $29(13.9 \%)$ & $0.54(0.18-1.64)$ & 0.269 \\
\hline Renal disease & $4(8.9 \%)$ & $15(9.2 \%)$ & 19 (9.1\%) & $0.96(0.30-3.06)$ & $>0.99$ \\
\hline Others & $14(31.1 \%)$ & 34 (20.9\%) & 48 (23.1\%) & $2.14(0.68-6.74)$ & 0.148 \\
\hline
\end{tabular}

${ }^{a}$ Number (frequency) unless noted otherwise; SD standard deviation. ${ }^{\mathrm{b}}$ Magnitude of difference between cases and control; odds ratio (for categorical data) or mean difference (for continuous data) plus $95 \%$ confidence interval. Empty cells means reference group; NA, difference cannot be calculated 
Table 3 Psychological characteristics and psychosocial examination results of 209 Saudi diabetic patients by diabetic foot ulcer status $^{\mathrm{a}}$

\begin{tabular}{|c|c|c|c|c|c|}
\hline & \multicolumn{2}{|c|}{ Diabetic foot ulcers } & \multirow{2}{*}{$\begin{array}{l}\text { Total } \\
(N=209)\end{array}$} & \multirow{2}{*}{$\begin{array}{l}\text { Magnitude of } \\
\text { difference }\end{array}$} & \multirow[t]{2}{*}{$p$-value } \\
\hline & Yes $(n=45)$ & No $(n=164)$ & & & \\
\hline \multicolumn{6}{|l|}{ Family history of psychiatric illness } \\
\hline No & $36(90.0 \%)$ & $141(88.1 \%)$ & $177(88.5 \%)$ & - & \multirow[t]{2}{*}{$>0.99$} \\
\hline Yes & $4(10.0 \%)$ & $19(11.9 \%)$ & $23(11.5 \%)$ & $0.83(0.26-2.58)$ & \\
\hline \multicolumn{6}{|l|}{ Visit to psychiatrist } \\
\hline No & $33(75.0 \%)$ & 149 (90.9\%) & $182(87.5 \%)$ & - & \multirow[t]{2}{*}{0.005} \\
\hline Yes & $11(25.0 \%)$ & $15(9.1 \%)$ & $26(12.5 \%)$ & $3.31(1.40-7.86)$ & \\
\hline \multicolumn{6}{|l|}{ Psychological/behavioral therapy } \\
\hline No & $33(82.5 \%)$ & 149 (93.1\%) & $182(91.0 \%)$ & - & \multirow[t]{2}{*}{0.058} \\
\hline Yes & $7(17.5 \%)$ & $11(6.9 \%)$ & $18(9.0 \%)$ & $2.87(1.04-7.97)$ & \\
\hline \multicolumn{6}{|l|}{ Psychiatric medications } \\
\hline No & $30(75.0 \%)$ & $148(93.1 \%)$ & $178(89.4 \%)$ & - & \multirow[t]{2}{*}{0.002} \\
\hline Yes & $10(25.0 \%)$ & $11(6.9 \%)$ & $21(10.6 \%)$ & $4.49(1.75-11.50)$ & \\
\hline \multicolumn{6}{|l|}{ Social support from family or friends } \\
\hline No & $10(25.0 \%)$ & $33(20.8 \%)$ & $43(21.6 \%)$ & - & \multirow[t]{3}{*}{0.062} \\
\hline Yes & $29(72.5 \%)$ & $99(62.3 \%)$ & $128(64.3 \%)$ & $0.97(0.43-2.19)$ & \\
\hline Somewhat & $1(2.5 \%)$ & $27(17.0 \%)$ & $28(14.1 \%)$ & $0.12(0.02-1.02)$ & \\
\hline \multicolumn{6}{|c|}{ Psychological deterioration after diagnosis of diabetes } \\
\hline No & $21(52.5 \%)$ & $93(58.1 \%)$ & $114(57.0 \%)$ & - & \multirow[t]{3}{*}{0.771} \\
\hline Yes & $10(25.0 \%)$ & $38(23.8 \%)$ & $48(24.0 \%)$ & $1.17(0.50-2.71)$ & \\
\hline Somewhat & $9(22.5 \%)$ & $29(18.1 \%)$ & $38(19.0 \%)$ & $1.37(0.57-3.33)$ & \\
\hline \multicolumn{6}{|c|}{ Improved family relationship after diagnosis of diabetes } \\
\hline No & $9(22.5 \%)$ & $54(33.8 \%)$ & $63(31.5 \%)$ & - & \multirow[t]{3}{*}{0.216} \\
\hline Yes & $23(57.5 \%)$ & $68(42.5 \%)$ & $91(45.5 \%)$ & $2.03(0.87-4.75)$ & \\
\hline Somewhat & $8(20.0 \%)$ & $38(23.8 \%)$ & $46(23.0 \%)$ & $1.26(0.45-3.57)$ & \\
\hline \multicolumn{6}{|l|}{ Quality of life; WHOQOL-BREF (mean \pm SD) } \\
\hline Domain 1: Physical health & $67.1 \pm 19.2$ & $71.1 \pm 16.4$ & $70.2 \pm 17.1$ & $-4.0(-9.7-1.7)$ & 0.263 \\
\hline Domain 2: Psychological & $75.4 \pm 14.9$ & $78.0 \pm 13.3$ & $77.4 \pm 13.7$ & $-2.6(-7.1-2.0)$ & 0.384 \\
\hline Domain 3: Social relationships & $77.3 \pm 16.5$ & $77.5 \pm 17.5$ & $77.4 \pm 17.3$ & $-0.2(-5.9-5.5)$ & 0.712 \\
\hline Domain 4: Environment & $75.1 \pm 16.7$ & $74.7 \pm 13.8$ & $74.8 \pm 14.5$ & $0.4(-4.4-5.2)$ & 0.672 \\
\hline Overall quality of life and general health & $75.6 \pm 13.2$ & $75.1 \pm 17.2$ & $75.2 \pm 16.4$ & $0.4(-5.0-5.9)$ & 0.891 \\
\hline Total: All above domains & $73.2 \pm 12.4$ & $74.8 \pm 12.0$ & $74.4 \pm 12.1$ & $-1.5(-5.5-2.5)$ & 0.539 \\
\hline \multicolumn{6}{|l|}{ Anxiety; HAD anxiety } \\
\hline Mean \pm SD & $4.7 \pm 4.6$ & $4.1 \pm 4.4$ & $4.2 \pm 4.5$ & $0.6(-0.9-2.1)$ & 0.355 \\
\hline Normal 0-7 & $34(75.6 \%)$ & $134(81.7 \%)$ & $168(80.4 \%)$ & - & \multirow[t]{2}{*}{0.357} \\
\hline Anxiety $>7$ & $11(24.4 \%)$ & $30(18.3 \%)$ & $41(19.6 \%)$ & $1.45(0.66-3.17)$ & \\
\hline \multicolumn{6}{|l|}{ Depression; HAD depression } \\
\hline Mean \pm SD & $5.7 \pm 4.3$ & $4.7 \pm 3.7$ & $4.9 \pm 3.9$ & $1.0(-0.3-2.3)$ & 0.200 \\
\hline Normal 0-7 & $30(66.7 \%)$ & $127(77.4 \%)$ & $157(75.1 \%)$ & - & \multirow[t]{2}{*}{0.139} \\
\hline Depression > 7 & $15(33.3 \%)$ & $37(22.6 \%)$ & $52(24.9 \%)$ & $1.72(0.84-3.53)$ & \\
\hline \multicolumn{6}{|l|}{ Somatic symptoms; PHQ-15 } \\
\hline Mean \pm SD & $6.8 \pm 5.7$ & $8.5 \pm 6.2$ & $8.1 \pm 6.1$ & $-1.6(-3.7-0.4)$ & 0.114 \\
\hline Minimal severity (0-4) & $18(40.0 \%)$ & $59(36.0 \%)$ & 77 (36.8\%) & - & 0.213 \\
\hline
\end{tabular}


Table 3 Psychological characteristics and psychosocial examination results of 209 Saudi diabetic patients by diabetic foot ulcer status $^{\mathrm{a}}$ (Continued)

\begin{tabular}{|c|c|c|c|c|c|}
\hline & \multicolumn{2}{|c|}{ Diabetic foot ulcers } & \multirow{2}{*}{$\begin{array}{l}\text { Total } \\
(N=209)\end{array}$} & \multirow{2}{*}{$\begin{array}{l}\text { Magnitude of } \\
\text { difference }^{b}\end{array}$} & \multirow[t]{2}{*}{$p$-value } \\
\hline & Yes $(n=45)$ & No $(n=164)$ & & & \\
\hline Low severity (5-9) & $16(35.6 \%)$ & $40(24.4 \%)$ & $56(26.8 \%)$ & $1.31(0.60-2.87)$ & \\
\hline Medium severity (10-14) & $7(15.6 \%)$ & $33(20.1 \%)$ & $40(19.1 \%)$ & $0.70(0.26-1.84)$ & \\
\hline High severity ( $\geq 15)$ & $4(8.9 \%)$ & $32(19.5 \%)$ & $36(17.2 \%)$ & $0.41(0.13-1.32)$ & \\
\hline \multicolumn{6}{|c|}{ Self-Management; SDSCA (mean \pm SD) } \\
\hline Diet & $44.8 \pm 39.3$ & $29.2 \pm 36.9$ & $32.6 \pm 37.9$ & $15.5(3.1-28.0)$ & 0.011 \\
\hline Exercise & $17.1 \pm 26.1$ & $18.7 \pm 27.2$ & $18.4 \pm 26.9$ & $-1.6(-10.5-7.4)$ & 0.351 \\
\hline Blood sugar testing & $55.4 \pm 37.9$ & $36.1 \pm 37.2$ & $40.2 \pm 38.1$ & $19.3(6.9-31.7)$ & 0.003 \\
\hline Foot care & $50.8 \pm 35.7$ & $23.4 \pm 33.7$ & $29.2 \pm 35.9$ & $27.4(16.0-38.8)$ & $<0.001$ \\
\hline Total & $42.2 \pm 20.3$ & $27.2 \pm 21.2$ & $30.4 \pm 21.8$ & $15.0(8.0-22.0)$ & $<0.001$ \\
\hline
\end{tabular}

These tools included the World Health Organization's Quality of Life Instrument-short version (WHOQOLBREF) for quality of life [22], the Hospital Anxiety and Depression (HAD) scale for the screening of anxiety and depression [23], the Patient Health Questionnaire Physical Symptoms (PHQ-15) for the severity of somatic symptoms [24], and the Summary of Diabetes Self-Care Activities (SDSCA) measure for diabetes self-management [25].

\section{Instrument validation}

The study questionnaire was (face and content) validated by experts in psychiatry, diabetes and epidemiology. A pilot study was then conducted with 20 participants, and the questionnaire was slightly modified based on feedback from the pilot study. Validated Arabic versions of the standardized tools mentioned above were used [2629]. These tools included WHOQOL-BREF [29], HAD [26], PHQ-15 [28], and SDSCA [27].

\section{Outcome evaluation}

The 26 items of WHOQOL-BREF were grouped into 4 domains: physical health, psychological health, social relationships, and environment [30]. Individual and total WHOQOL-BREF scores were transformed into a 100point scale, with higher scores indicating better quality of life. HAD scores for depression and anxiety were calculated from 7 questions each, with a range between 0 and 21 points. Depression and anxiety were indicated by HAD scores above 7 [31]. The PHQ-15 score was calculated from 15 questions, with a range between 0 and 30 . Using the PHQ-15 score, the severity of somatic symptoms was categorized as minimal (0-4), low (5-9), medium (10-14), and high $(\geq 15)$ [24]. The 8 items of the SDSCA were grouped into 4 groups: diet, exercise, blood sugar testing, and foot care in diabetic patients. As there are no cutoff points, the average SDSCA scores were presented to indicate the frequency of proper selfmanagement of diabetes during the last week [25].

\section{Statistical analysis}

Data are presented as frequencies and percentages for categorical data and the mean and standard deviation (SD) for continuous data. For the first objective, the quality of life and its possible demographic, clinical, and psychological determinants were compared between those with and without diabetic foot ulcer, using the chisquare test or Fisher's exact test (as appropriate) for categorical data and Student's t-test or the Mann-Whitney $\mathrm{U}$ Test (as appropriate) for continuous data. For the second objective, correlations between quality of life and other psychosocial determinants such as anxiety and depression were examined using the Spearman correlation coefficient. To identify which of these psychosocial determinants were independent determinants of quality of life, a multivariate general linear regression model was run after adjusting for demographic and clinical characteristics (as described in the footnote of Table 4). The outcome was the quality of life, the grouping factor was diabetic foot ulcers, and the predictors of interest were psychosocial determinants; anxiety, depression, somatic symptoms, and self-management (Table 4 ). All $P$-values were two-tailed. A $P$-value $<0.05$ was considered significant. SPSS software (release 25.0, Armonk, NY: IBM Corp) was used for statistical analysis.

\section{Results}

Demographic characteristics by diabetic foot ulcer group A total of 209 patients (45 cases and 164 controls) were included in the current analysis. The demographic 
Table 4 Multivariate linear regression for the determinants of quality of life among 209 Saudi diabetic patients

\begin{tabular}{|c|c|c|c|c|c|}
\hline & \multirow{2}{*}{$\begin{array}{l}\text { Unstandardized } \\
\text { beta }\end{array}$} & \multirow{2}{*}{$\begin{array}{l}\text { Standard } \\
\text { error of } \\
\text { beta }\end{array}$} & \multicolumn{2}{|c|}{ 95\% confidence interval (CI) } & \multirow{2}{*}{$\begin{array}{l}p- \\
\text { value }\end{array}$} \\
\hline & & & Lower Cl & Upper Cl & \\
\hline Anxiety; HAD anxiety & -0.034 & 0.029 & -0.094 & 0.025 & 0.251 \\
\hline Depression; HAD depression & -0.069 & 0.030 & -0.129 & -0.009 & 0.026 \\
\hline Somatic symptoms; PHQ-15 & -0.046 & 0.037 & -0.120 & 0.029 & 0.224 \\
\hline Self-management; SDSCA & 0.036 & 0.032 & -0.029 & 0.102 & 0.270 \\
\hline Diabetic foot ulcer & 0.989 & 1.059 & 0.882 & 1.108 & 0.848 \\
\hline
\end{tabular}

Abbreviations as listed in Table 3

Adjusted for age, gender, BMI, marital status, educational level, occupation, monthly income, number of family members, HBA1c level, and number of comorbid diseases

characteristics of the study patients are shown in Table 1. The average age was $56.2 \pm 11.7$ years, and $40.0 \%$ of the patients were 60 years or older. Approximately $55.5 \%$ were female. The average body mass index (BMI) was $31.9 \pm 7.6$, and $55.4 \%$ of the patients were considered obese. The majority (78.9\%) of patients were currently married. The patients had a wide range of educational backgrounds; $20.3 \%$ were illiterate, $29.7 \%$ had a less than high school level of education, $23.3 \%$ had a high school education, and $26.7 \%$ had a university education or above. The majority of patients were either unemployed (42.6\%) or housewives (34.4\%). The majority of the patients (69.6\%) had a monthly income less than SR 10, 000 . The average family size was $7.0 \pm 3.3$, and the majority of the patients (87.9\%) lived with their families. None of the above demographic characteristics were significantly different between cases and controls.

\section{Clinical characteristics by diabetic foot ulcer group}

The clinical characteristics of the examined patients are shown in Table 2. The majority $(66.5 \%)$ of the patients had type 2 diabetes. The average level of glycated hemoglobin (HBA1c) was $8.6 \pm 2.2$, and only $41.3 \%$ of the patients had controlled HBA1c $(<8)$. The average age at diabetes diagnosis was $41.6 \pm 12.1$ years. The majority (71.3\%) had a family history of diabetes. The most frequent symptoms were peripheral numbness (55.4\%), tiredness without working (46.6\%), peripheral tingling (44.6\%), and peripheral hypo- or hyperthermia (44.1\%). The average number of comorbid diseases was $2.8 \pm 2.0$, and $11.5 \%$ of patients had no comorbid diseases and $48.1 \%$ had three or more diseases. The most frequent comorbid diseases were hypercholesterolemia (56.3\%), hypertension (50.0\%), joint disease (34.1\%), cataracts (20.7\%), and cardiovascular diseases (19.7\%). Compared with controls, cases had a younger age at diabetes diagnosis $(37.6 \pm 12.0$ versus $42.7 \pm 12.0, p=0.014)$, were less likely to have type 1 diabetes $(8.9 \%$ versus $20.1 \%, p=0.033)$ or to control their diabetes $(21.7 \%$ versus $45.9 \%, p=0.034)$, and were more likely to have peripheral numbness $(79.5 \%$ versus $48.8 \%$, $p<0.001)$, peripheral painlessness $(38.6 \%$ versus $10.0 \%$, $p<0.001)$, and retinal disease $(31.1 \%$ versus $12.3 \%, p=$ $0.002)$. Amputation was reported only among those with diabetic foot ulcers (22.7\%).

Psychological determinants by diabetic foot ulcer group Psychological characteristics and psychosocial examinations of the examined patients are shown in Table 3. Compared with controls, cases were more likely to visit a psychiatrist $(25.0 \%$ versus $9.1 \%, p=0.005)$ and to take psychiatric medications (25.0\% versus $6.9 \%$, $\mathrm{p}=0.002)$. There were no significant differences between cases and controls regarding family history of psychiatric illness, receiving psychological/behavioral therapy, social support from family or friends, psychological deterioration after diagnosis of diabetes, or the status of family relationships after diagnosis of diabetes. The average overall WHOQOL-BREF score was $74.4 \pm 12.1 \%$, with no differences between cases and controls in individual or overall scores. Approximately $19.6 \%$ of the patients had anxiety and $24.9 \%$ had depression, with no differences between cases and controls. Out of a maximum of 30, the average PHQ-15 score was $8.1 \pm 6.1$, with one-third of the patients having either moderate (19.1\%) or severe (17.2\%) somatic symptoms. The severity of somatic symptoms was slightly lower in cases than in controls, but the differences were not significant. The overall frequency of proper self-management of diabetes was significantly higher in cases than in controls (42.2 \pm 20.3 versus $27.2 \pm 21.2, p<0.001)$. This finding was true for all components of self-management, with the exception of physical activity.

\section{The correlations of quality of life with psychosocial determinants}

The correlations of quality of life with psychosocial determinants and comorbidities are shown in Table 5. There were significant strong negative correlations between quality of life and anxiety, depression, and the severity of somatic symptoms. For example, the correlation coefficients of the correlations of the total WHOQOL-BREF score (all 
Table 5 Correlations of quality of life with other psychosocial examination results and comorbidities of 209 Saudi diabetic patients by diabetic foot (DF) ulcer status

\begin{tabular}{|c|c|c|c|c|c|c|}
\hline & Physical health & Psychological & Social relationships & Environment & Overall & Total (all domains) \\
\hline \multicolumn{7}{|l|}{ DM with DF } \\
\hline Anxiety; HAD anxiety & $-0.381^{* *}$ & $-0.363^{*}$ & -0.104 & $-0.396^{* *}$ & $-0.488^{* *}$ & $-0.494^{* *}$ \\
\hline Depression; HAD depression & $-0.565^{* *}$ & $-0.512^{* *}$ & -0.212 & $-0.453^{* *}$ & $-0.552^{* *}$ & $-0.624^{* *}$ \\
\hline Somatic symptoms; PHQ-15 & $-0.353^{*}$ & -0.179 & -0.109 & $-0.321^{*}$ & -0.197 & $-0.401^{* *}$ \\
\hline \multicolumn{7}{|l|}{ Self-management; SDSCA } \\
\hline Diet & -0.133 & 0.243 & 0.070 & 0.049 & $0.441^{* *}$ & 0.065 \\
\hline Exercise & 0.132 & -0.001 & 0.156 & 0.192 & $0.313^{*}$ & 0.190 \\
\hline Blood sugar testing & -0.159 & -0.109 & -0.095 & 0.118 & -0.083 & -0.085 \\
\hline Foot care & 0.155 & 0.106 & -0.100 & 0.129 & 0.102 & 0.203 \\
\hline Total & -0.010 & 0.139 & -0.021 & 0.189 & $0.334^{*}$ & 0.161 \\
\hline Number of comorbid diseases & 0.096 & 0.047 & -0.039 & -0.065 & -0.020 & -0.018 \\
\hline \multicolumn{7}{|l|}{ DM without DF } \\
\hline Anxiety; HAD anxiety & $-0.562^{* *}$ & $-0.547^{* *}$ & $-0.350^{* *}$ & $-0.362^{* *}$ & $-0.365^{* *}$ & $-0.587^{* *}$ \\
\hline Depression; HAD depression & $-0.521^{* *}$ & $-0.488^{* *}$ & $-0.411^{* *}$ & $-0.385^{* *}$ & $-0.341^{* *}$ & $-0.574^{* *}$ \\
\hline Somatic symptoms; PHQ-15 & $-0.654^{* *}$ & $-0.462^{* *}$ & $-0.324^{* *}$ & $-0.368^{* *}$ & $-0.352^{* *}$ & $-0.582^{* *}$ \\
\hline \multicolumn{7}{|l|}{ Self-management; SDSCA } \\
\hline Diet & 0.078 & 0.127 & 0.052 & $0.156^{*}$ & 0.084 & 0.108 \\
\hline Exercise & $0.226^{* *}$ & 0.005 & -0.043 & 0.073 & 0.034 & 0.109 \\
\hline Blood sugar testing & -0.087 & -0.049 & 0.101 & -0.007 & -0.033 & -0.064 \\
\hline Foot care & 0.006 & 0.138 & 0.146 & 0.144 & 0.109 & 0.127 \\
\hline Total & 0.036 & 0.080 & 0.059 & 0.111 & 0.057 & 0.068 \\
\hline Number of comorbid diseases & $-.411^{* *}$ & -0.149 & -0.120 & -0.106 & -0.086 & $-0.253^{* *}$ \\
\hline \multicolumn{7}{|l|}{ Total } \\
\hline Anxiety; HAD anxiety & $-0.525^{* *}$ & $-0.509^{* *}$ & $-0.293^{* *}$ & $-0.368^{* *}$ & $-0.387^{* *}$ & $-0.559^{* *}$ \\
\hline Depression; HAD depression & $-0.534^{* *}$ & $-0.491^{* *}$ & $-0.376^{* *}$ & $-0.397^{* *}$ & $-0.382^{* *}$ & $-0.582^{* *}$ \\
\hline Somatic symptoms; PHQ-15 & $-0.575^{* *}$ & $-0.396^{* *}$ & $-0.274^{* *}$ & $-0.358^{* *}$ & $-0.319^{* *}$ & $-0.532^{* *}$ \\
\hline \multicolumn{7}{|l|}{ Self-management; SDSCA } \\
\hline Diet & 0.016 & 0.135 & 0.038 & 0.127 & $0.148^{*}$ & 0.084 \\
\hline Exercise & $0.212^{* *}$ & 0.009 & 0.006 & 0.094 & 0.092 & $0.137^{*}$ \\
\hline Blood sugar testing & -0.118 & -0.065 & 0.050 & 0.024 & -0.046 & -0.073 \\
\hline Foot care & -0.002 & 0.099 & 0.085 & 0.136 & 0.087 & 0.111 \\
\hline Total & 0.010 & 0.073 & 0.048 & $0.140^{*}$ & 0.095 & 0.079 \\
\hline Number of comorbid diseases & $-.300^{* *}$ & -0.105 & -0.106 & -0.092 & -0.075 & $-0.201^{* *}$ \\
\hline
\end{tabular}

Correlation is significant at the 0.05 level $\left(^{*}\right)$ or the 0.01 level $\left(^{* *}\right)$. Abbreviations as listed in Table 3

domains) with the HAD anxiety, HAD depression, and PHQ-15 scores in all patients were $-0.559(p<0.001)$, $0.582(p<0.001)$, and $-0.532(p<0.001)$, respectively. These numbers were very similar in cases and controls. On the other hand, some domains of quality of life had significant mild to moderate positive correlations with diet and exercise in both cases and controls. For example, the overall WHOQOL-BREF score in cases correlated with the scores on the diet and exercise components of the SDSCA ( $r=$
0.441, $p=0.002$ and $r=0.313, p=0.036$, respectively). There were significant mild negative correlations between quality of life (total WHOQOL-BREF score) and the number of comorbid diseases in controls $(-0.253, p=0.001)$ but not in cases $(-0.018, p=0.908)$.

\section{Multivariate analysis for quality of life}

In multivariate linear regression analysis adjusting for demographic and clinical characteristics of the patients, 
only depression remained a significant independent determinant of quality of life. With each one point increase in the HAD score for depression, there was a decrease by 0.069 in the total WHOQOL-BREF scores of quality of life $(p=0.024)$. The association between depression and quality of life remained irrespective of the status of diabetic foot ulcers, which by itself was not a significant determinant of quality of life (unstandardized beta = $0.989, p=0.848)$, please, see Table 4 .

\section{Discussion}

The main finding in the current study was the lack of difference in quality of life between those with and without diabetic foot ulcers. While this finding contradicts the majority of previous studies that showed lower levels of quality of life among patients with diabetic foot ulcers compared to those without diabetic foot ulcers [12-14], several important differences should be highlighted. The majority of previous studies used generic tools, such as the 36-item ShortForm Health Survey (SF-36) [12, 32], which focus on health domains with less emphasis on the cultural, psychological, and environmental context of the quality of life compared to the WHOQOL-BREF [33]. For example, in a recent meta-analysis of 12 studies that examined quality of life among patients with diabetic foot ulcers, 9 studies used SF-36 and one study used the WHOQOL-BREF [12]. Additionally, the WHOQOL-BREF measures self-perception of overall quality of life and general health, which could be influenced by expectations, standards and concerns that can be different in different cultures. While it is difficult to compare quality of life using different tools, the level of quality of life in the current study was probably higher than that seen in previous studies. For example, the average scores in the current study were $>70 \%$ for all WHOQOL-BREF domains, compared with 50 or less in most of the domains in previous studies [12, 14, 32]. This difference may be related to the better social support that the patients in both groups received within a generally conservative community characterized by the presence of extended families and religious connectedness [15]. For example, only $12.1 \%$ of our patients lived alone, close to $80 \%$ received social support from family or friends, and close to $70 \%$ reported improved family relationships after their diagnosis of diabetes. The higher levels of quality of life in both groups in the current study may have masked the difference between the two groups, if any.

Unexpectedly, the current finding showed lack of differences in anxiety, depressive symptoms, and severity of somatic symptoms between those with and without diabetic foot ulcers. This was inconsistent with studies that linked anxiety and depressive symptoms with poor quality of life among patients with diabetic foot ulcers [17, 18]. The observed lack of differences in the above psychosocial determinants between the groups of diabetic foot ulcers may explain at least partially the observed lack of difference in quality of life between the groups of diabetic foot ulcers.

Self-management is known as a core preventive measure for diabetic foot ulcers [5, 6]. Unexpectedly, patients with diabetic foot ulcers in the current study had better self-management. Moreover, patients with diabetic foot ulcers who had better self-management had also poor glycemic control. While it is difficult to explain such discrepancy, it may reflect a temporary increased willingness of patients with diabetic foot ulcers to follow selfmanagement recommendations to treat current ulcer and prevent its recurrence [6]. Additionally, the selfreported nature of the SDSCA measure should also be considered.

Psychological factors in the current study were generally associated with poor quality of life. Similarly, several studies showed that depressive and anxiety symptoms negatively impact quality of life in patients with diabetic foot ulcers $[17,18]$ and those with diabetes but without diabetic foot ulcers [34, 35]. The development of depression among diabetic patients has been shown to augment the negative impact of diabetes on the physical and mental components of quality of life [35]. This augmentation may be mediated by poor adherence to medication indications, healthy lifestyle, and metabolic dysfunction $[35,36]$.

The severity of somatic symptoms in the current study was strongly correlated with poor quality of life in univariate analysis. While this correlation has been shown in other types of patients [37], we could not identify studies that examined the severity of somatic symptoms in relation to quality of life among patients with diabetic foot ulcers. The negative impact of somatic symptoms on quality of life may be mediated by pain and psychological symptoms [12, 37, 38]. Interestingly, the impact of pain on activity is part of the physical component of quality of life in both the WHOQOL-BREF and SF-36 [12, 30]. Similar to previous studies, diabetes self-management in the current study was associated with better quality of life [39]. Quality of life and self-management have been shown in previous studies to be positively associated among patients with [39] and without diabetic foot ulcers [40].

The current study is considered the first local study to examine quality of life and its psychosocial and related determinants in a controlled design. Additionally, the study outcomes were measured using standard validated tools. Nevertheless, a number of 
limitations are acknowledged. The case-control design does not prove causations but rather associations. This highlights the need for future longitudinal studies to confirm the current findings. As a two-center single-institution study, the current findings should be generalized cautiously. While the sample size had sufficient power to examine the main study objective, it may be underpowered for studying secondary objectives. The self-reported nature of the outcome tools makes it difficult to exclude recall bias. However, the current study is a valuable addition to the research on quality of life among patients with diabetes.

\section{Conclusion}

In conclusion, quality of life was similar in patients with and without diabetic foot ulcers. Anxiety, depressive symptoms, and the severity of somatic symptoms were similar in both groups but were strongly correlated with poor quality of life in both groups. Self-management which was associated with diabetic foot ulcers had a positive but weak correlation with quality of life. Depressive symptoms were independent determinant of poor quality of life. There may be a need for interventional studies to assess the impact of preventive programs focused on depression and anxiety on different domains of quality of life.

\section{Abbreviations \\ HAD: The Hospital Anxiety and Depression scale; KSUMC: King Saud University Medical City; PHQ-15: The Patient Health Questionnaire Physical Symptoms; SDSCA: The Summary of Diabetes Self-Care Activities; WHOQOL- BREF: The World Health Organization's Quality of Life Instrument-short version}

\section{Acknowledgments}

The authors would like to acknowledge the College of Medicine Research Center, Deanship of Scientific Research, King Saud University, Riyadh, Kingdom of Saudi Arabia for supporting this study. Furthermore, the authors express their gratitude to Dr. Aiman El-Saed for his assistance in data analysis and to the students (Abdulrahman Abu Sittah, Khalid Aljedia, Khalid Al-Enezi, Ahmed Al-Enezi) for their assistance in data collection.

\section{Authors' contributions}

FA designed the study; supervised the data collection, entry and statistical analysis; and co-wrote the final draft of the manuscript. RL, NA, NA, LA and DA participated effectively in designing the study, data collection, entry and analysis and writing the paper. All authors read and approved the final manuscript.

\section{Funding}

None.

\section{Availability of data and materials}

All data generated or analysed during this study are included in this published article.

\section{Ethics approval and consent to participate}

The study obtained all required ethical approvals from the institutional review board at Faculty of Medicine at King Saud University in Riyadh. Adult patients with diabetes receiving diabetic care at the diabetic center or the primary care clinic of KSUMC were asked to consent to participate. Patients with serious late complications of diabetes, such as dialysis and blindness, were excluded. Patients with difficulty communicating, such as those with a language barrier or severe cognitive impairment, were excluded. There were no exclusions based on the type of diabetes, comorbidities, or glycemic control.

\section{Consent for publication}

Not applicable.

\section{Competing interests}

The authors declare that they have no competing interests.

\section{Author details}

${ }^{1}$ Department of Psychiatry, King Saud University, Riyadh, Saudi Arabia. ${ }^{2}$ Department of Psychiatry, College of medicine, King Saud University, P.O. Box: 7805, Riyadh Postcode:11472, Saudi Arabia. ${ }^{3}$ College of Medicine, King Saud University, Riyadh, Saudi Arabia.

Received: 6 August 2019 Accepted: 2 December 2019

Published online: 10 December 2019

\section{References}

1. International Diabetes Federation. IDF Diabetes Atlas. 8th ed; 2017. URL: https://www.idf.org/component/attachments/attachments.html?id=1405 \&task=download (Last Accessed 1 Nov 2019)

2. Bus SA, van Netten JJ, Lavery LA, Monteiro-Soares M, Rasmussen A, Jubiz Y, et al. IWGDF guidance on the prevention of foot ulcers in at-risk patients with diabetes. Diabetes Metab Res Rev. 2016:32(Suppl 1):16-24.

3. Mairghani M, Elmusharaf K, Patton D, Burns J, Eltahir O, Jassim G, et al. The prevalence and incidence of diabetic foot ulcers among five countries in the Arab world: a systematic review. J Wound Care. 2017;26:S27-34.

4. Zhang P, Lu J, Jing Y, Tang S, Zhu D, Bi Y. Global epidemiology of diabetic foot ulceration: a systematic review and meta-analysis. Ann Med. 2016:49:106-16.

5. Bonner T, Foster M, Spears-Lanoix E. Type 2 diabetes-related foot care knowledge and foot self-care practice interventions in the United States: a systematic review of the literature. Diabe Foot Ankle. 2016;7: 29758.

6. van Netten JJ, Price PE, Lavery LA, Monteiro-Soares M, Rasmussen A, Jubiz Y, et al. Prevention of foot ulcers in the at-risk patient with diabetes: a systematic review. Diabetes Metab Res Rev. 2016;32(Suppl 1):84-98.

7. Martins-Mendes D, Monteiro-Soares M, Boyko EJ, Ribeiro M, Barata P, Lima J, et al. The independent contribution of diabetic foot ulcer on lower extremity amputation and mortality risk. J Diabetes Complicat. 2014;28:632-8.

8. Jupiter DC, Thorud JC, Buckley CJ, Shibuya N. The impact of foot ulceration and amputation on mortality in diabetic patients. I: from ulceration to death, a systematic review. Int Wound J. 2016;13:892-903.

9. Al-Rubeaan K, Almashouq MK, Youssef AM, Al-Qumaidi H, Al Derwish M, Ouizi S, et al. All-cause mortality among diabetic foot patients and related risk factors in Saudi Arabia. PLoS One. 2017:12:e0188097.

10. Driver VR, Fabbi M, Lavery LA, Gibbons G. The costs of diabetic foot: the economic case for the limb salvage team. J Am Podiatr Med Assoc. 2010; 100:335-41.

11. van Acker K, Leger $P$, Hartemann A, Chawla A, Siddiqui MK. Burden of diabetic foot disorders, guidelines for management and disparities in implementation in Europe: a systematic literature review. Diabetes Metab Res Rev. 2014:30:635-45.

12. Khunkaew S, Fernandez R, Sim J. Health-related quality of life among adults living with diabetic foot ulcers: a meta-analysis. Qual Life Res. 2019;28:1413-27.

13. Goodridge D, Trepman E, Embil JM. Health-related quality of life in diabetic patients with foot ulcers: literature review. J Wound Ostomy Continence Nurs. 2005;32:368-77.

14. AlSadrah SA. Impaired quality of life and diabetic foot disease in Saud patients with type 2 diabetes: a cross-sectional analysis. SAGE Open Med. 2019:7:2050312119832092.

15. Alzahrani HA, Sehlo MG. The impact of religious connectedness on healthrelated quality of life in patients with diabetic foot ulcers. J Relig Health. 2013;52:840-50.

16. Fejfarová V, Jirkovská A, Dragomirecká E, Game F, Bém R, Dubský M, et al. Does the diabetic foot have a significant impact on selected psychological or social characteristics of patients with diabetes mellitus? J Diab Res. 2014; 2014:371938. 
17. Pedras S, Carvalho R, Pereira MG. Predictors of quality of life in patients with diabetic foot ulcer: the role of anxiety, depression, and functionality. J Health Psychol. 2016;23:1488-98.

18. Simson U, Nawarotzky U, Porck W, Friese G, Schottenfeld-Naor Y, Hahn S, et al. Depression, anxiety, quality of life and type D pattern among inpatients suffering from diabetic foot syndrome. Psychotherapie Psychosomatik Medizinische Psychologie. 2008;58:44-50.

19. Al-Rubeaan K, Al Derwish M, Ouizi S, Youssef AM, Subhani SN, Ibrahim HM, et al. Diabetic foot complications and their risk factors from a large retrospective cohort study. PLoS One. 2015;10:e0124446.

20. Hu Y, Bakhotmah BA, Alzahrani OH, Wang D, Hu FB, Alzahrani HA. Predictors of diabetes foot complications among patients with diabetes in Saudi Arabia. Diabetes Res Clin Pract. 2014;106:286-94.

21. Sehlo MG, Alzahrani $\mathrm{OH}$, Alzahrani HA. Illness invalidation from spouse and family is associated with depression in diabetic patients with first superficial diabetic foot ulcers. Int J Psychiatry Med. 2016;51:16-30.

22. The WHOQOL. Group. Development of the World Health Organization WHOQOL-BREF quality of life assessment. The WHOQOL group. Psychol Med. 1998;28:551-8.

23. Zigmond AS, Snaith RP. The hospital anxiety and depression scale. Acta Psychiatr Scand. 1983;67:361-70.

24. Kroenke K, Spitzer R, Williams J. The PHQ-15: validity of a new measure for evaluating the severity of somatic symptoms. Psychosom Med. 2002; 64:258-66.

25. Toobert DJ, Hampson SE, Glasgow RE. The summary of diabetes self-care activities measure: results from 7 studies and a revised scale. Diabetes Care. 2000;23:943-50.

26. Al Aseri ZA, Suriya MO, Hassan HA, Hasan M, Sheikh SA, Al Tamimi A, et al. Reliability and validity of the hospital anxiety and depression scale in an emergency department in Saudi Arabia: a cross-sectional observational study. BMC Emerg Med. 2015;15(1):28-33.

27. Al Johani KA, Kendall GE, Snider PD. Self-management practices among type 2 diabetes patients attending primary health-care centres in Medina, Saudi Arabia. East Mediterr Health J. 2015;21:621-8.

28. AlHadi AN, AlAteeq DA, Al-Sharif E, Bawazeer HM, Alanazi H, AlShomrani AT, et al. An arabic translation, reliability, and validation of patient health questionnaire in a Saudi sample. Ann General Psychiatry. 2017;16:32.

29. Ohaeri JU, Awadalla AW. The reliability and validity of the short version of the $\mathrm{WHO}$ quality of life instrument in an Arab general population. Ann Saudi Med. 2009;29:98-104.

30. University of Washington. WHOQOL-BREF-The World Health Organization Quality of Life. June 1997. U.S. Version. URL: http://depts.washington.edu/ seaqol/docs/WHOQOL-BREF\%20and\%20Scoring\%20Instructions.pdf. (Last Accessed 1 Nov 2019).

31. Stern AF. The hospital anxiety and depression scale. Occup Med (Lond). 2014:64:393-4.

32. Hogg FR, Peach G, Price P, Thompson MM, Hinchliffe RJ. Measures of health-related quality of life in diabetes-related foot disease: a systematic review. Diabetologia. 2012;55:552-65.

33. Nemcova J, Hlinkova E, Farsky I, Ziakova K, Jarosova D, Zelenikova R, et al. Quality of life in patients with diabetic foot ulcer in Visegrad countries. J Clin Nurs. 2017;26:1245-56.

34. Paschalides C, Wearden AJ, Dunkerley R, Bundy C, Davies R, Dickens CM. The associations of anxiety, depression and personal illness representations with glycaemic control and health-related quality of life in patients with type 2 diabetes mellitus. J Psychosom Res. 2004;57:557-64.

35. Goldney RD, Phillips PJ, Fisher LJ, Wilson DH. Diabetes, depression, and quality of life: a population study. Diabetes Care. 2004;27:1066-70.

36. Lustman PJ, Clouse RE. Depression in diabetic patients: the relationship between mood and glycemic control. J Diabetes Complicat. 2005;19:113-22.

37. Sogutlu A, Levenson JL, McClish DK, Rosef SD, Smith WR. Somatic symptom burden in adults with sickle cell disease predicts pain, depression, anxiety, health care utilization, and quality of life: the PiSCES project. Psychosomatics. 2011:52:272-9.

38. Kocalevent R-D, Hinz A, Brähler E. Standardization of a screening instrument (PHQ-15) for somatization syndromes in the general population. BMC psychiatry. 2013;13:91.

39. Navicharern R. Diabetes self-management, fasting blood sugar and quality of life among type 2 diabetic patients with foot ulcers. J Med Assoc Thai. 2012;95:156-62.
40. Timar R, Velea I, Timar B, Lungeanu D, Oancea C, Roman D, et al. Factors influencing the quality of life perception in patients with type 2 diabetes mellitus. Patient Preference Adherence. 2016;10:2471-7.

\section{Publisher's Note}

Springer Nature remains neutral with regard to jurisdictional claims in published maps and institutional affiliations.
Ready to submit your research? Choose BMC and benefit from:

- fast, convenient online submission

- thorough peer review by experienced researchers in your field

- rapid publication on acceptance

- support for research data, including large and complex data types

- gold Open Access which fosters wider collaboration and increased citations

- maximum visibility for your research: over $100 \mathrm{M}$ website views per year

At BMC, research is always in progress.

Learn more biomedcentral.com/submissions 